\title{
Eficácia dos extratos pirolenhosos de cana-de-açúcar (Saccharum officinarum L.) e eucalipto (Eucalyptus spp.) no controle in vitro de patógenos da soja
}

\author{
Suelen Pieta $^{1} \oplus$, Walber Luiz Gavassoni ${ }^{1} \oplus$, Lilian Maria Arruda Bacchi ${ }^{1} \oplus$, Rodrigo Aparecido Jordan ${ }^{1} \oplus$
}

\begin{abstract}
${ }^{1}$ Universidade Federal da Grande Dourados (UFGD), Faculdade de Ciências Agrárias, Unidade II: Rodovia Dourados/Itahum, Km 12, Cidade Universitária, Faculdade de Ciências Agrárias, Caixa Postal: 364, CEP: 79.804-970, Dourados, MS, Brasil

Autor para correspondência: Suelen Pieta (suelen_pieta@hotmail.com)

Data de chegada: 17/07/2017. Aceito para publicação em: 19/11/2020.
\end{abstract}

$10.1590 / 0100-5405 / 182794$

O Brasil é segundo maior produtor mundial de soja [Glycine $\max (\mathrm{L}$.$) Merr.] e os índices de produção são destaque no$ cenário agrícola internacional. Das limitações impostas à sua produção, as doenças se apresentam como uma das principais ameaças à cultura interferindo na sua produtividade. Dentre as doenças destacam-se o mofo branco (Sclerotinia sclerotiorum (Lib.) de Bary), a antracnose (Colletotrichum truncatum (Schw.) Andrus \& Moore) e a podridão de carvão (Macrophomina phaseolina (Tassi) Goidanish) (6). As medidas de controle são objeto de pesquisas constantes e produtos oriundos de fontes renováveis, como extratos pirolenhosos (EP), podem ser alternativas promissoras no manejo de doenças de plantas (10). O EP é um subproduto obtido a partir da produção do carvão vegetal, resultante da condensação dos vapores sob a forma de fumos, originados durante o processo de pirólise. Pode ser obtido de diferentes espécies vegetais, como bambu, eucalipto, pinus e cana-de-açúcar (2). É composto por água em sua maior parte $(80 \%)$ e uma mistura complexa de mais de 200 compostos orgânicos, possui ação fungicida, nematicida e também é utilizado como fertilizante orgânico $(2,3)$. Desta forma, o objetivo do presente estudo foi avaliar a eficácia de diferentes concentrações dos extratos pirolenhosos da cana-de-açúcar (Saccharum officinarum L.) e do eucalipto (Eucalyptus spp.) no desenvolvimento in vitro dos fungos $S$. sclerotiorum, M. phaseolina e C. truncatum. Os experimentos foram realizados no Laboratório de Microbiologia Agrícola e Fitopatologia (LAMAF) da Universidade Federal da Grande Dourados (UFGD) e conduzidos entre abril de 2015 e setembro de 2016. Os extratos destilados foram fornecidos pela empresa Bioware Tecnologia (Campinas, SP). O inóculo de $S$. sclerotiorum foi obtido em área naturalmente infestada da cultura do cártamo (Carthamus tinctorius L.). Os isolados de M. phaseolina e C. truncatum foram obtidos da micoteca do LAMAF-UFGD. O delineamento foi inteiramente casualizado com seis repetições e seis tratamentos para cada patógeno. As concentrações testadas foram 0, 1000, 2000, 3000, 4000 e $5000 \mu \mathrm{g} / \mathrm{mL}$. Discos de micélio $(5 \mathrm{~mm}$ ) de colônias puras dos isolados foram transferidos para o centro de placas de Petri que foram então incubadas em câmara B.O.D (Demanda Biológica de Oxigênio) à temperatura de $25^{\circ} \mathrm{C}$ e fotoperíodo de 12 horas. As avaliações iniciaram a partir do momento em que a testemunha de cada patógeno apresentou crescimento micelial. Avaliou-se o crescimento e o índice de velocidade do crescimento micelial (IVCM). Foi realizada análise de variância (ANOVA), seguida do teste de Tukey, com o auxílio do programa SISVAR 5.6 (4). Constatada a significância pelo teste
F, a análise de regressão foi realizada para o fator concentração para cada tempo de avaliação, dias após início da incubação, com o programa SigmaPlot 12.5. Concentrações crescentes de extratos pirolenhosos de cana-de-açúcar e eucalipto afetaram negativamente o desenvolvimento dos fungos $S$. sclerotiorum, M. phaseolina e C. truncatum (Figura 1). Verificou-se que o EP de cana-de-açúcar limitou o crescimento dos patógenos com o aumento das concentrações, resultando em colônias de menor diâmetro. Um padrão semelhante foi observado para a velocidade do crescimento micelial (IVCM). O extrato pirolenhoso apresentou fungitoxidade nas diferentes concentrações, inibindo o desenvolvimento dos patógenos e interferindo na velocidade de colonização do meio de cultura. Santos Junior et al. (9), avaliando in vitro a fungitoxidade de diferentes concentrações de extrato pirolenhoso de teca (Tectona grandis), sobre o crescimento micelial de Rhizoctonia solani, também observaram que em todas as concentrações utilizadas, o EP proporcionou ação fungitóxica sobre o fungo. No experimento com o EP de eucalipto, na avaliação do crescimento micelial de M. phaseolina e C. truncatum, verificou-se que houve redução no diâmetro das colônias dos fungos conforme as concentrações aumentaram e, para a concentração de $5000 \mu \mathrm{g} / \mathrm{mL}$, não foi observado desenvolvimento fúngico às $24 \mathrm{~h}$. Quanto ao IVCM, com o aumento das concentrações a velocidade do desenvolvimento fúngico diminuiu em ambos os patógenos estudados. Resultados semelhantes foram encontrados por Rodrigues (7), avaliando o potencial do extrato pirolenhoso de teca (Tectona grandis) no crescimento micelial in vitro de Colletotrichum gloeosporioides. $\mathrm{O}$ autor relata que houve redução na velocidade e no crescimento micelial fúngico de acordo com a elevação das doses. No presente estudo, para $S$. sclerotiorum, no primeiro período de avaliação (24 h), as concentrações de 1000, 2000 e 3000 $\mu \mathrm{g} / \mathrm{mL}$ de EP de eucalipto favoreceram o desenvolvimento fúngico, porém, a partir das concentrações de 4000 e $5000 \mu \mathrm{g} /$ $\mathrm{mL}$, o patógeno apresentou colônias com diâmetros menores. Comportamento semelhante foi observado para a velocidade do crescimento micelial. Foi possível verificar neste estudo que os patógenos apresentaram sensibilidade diferenciada quando submetidos a determinado extrato. Theisen et al. (11) avaliando os efeitos de duas formulações de EP, uma destilada e outra bruta decantada, na supressão de doenças da fase inicial de plântulas de soja, mostram que as melhores respostas foram obtidas com a formulação destilada. O extrato suprimiu alguns fungos frequentes como Alternaria e Penicillium, destacando a supressão para S. sclerotiorum. Pelo fato do EP ser composto por diversos componentes de ação biológica, os autores propõem 

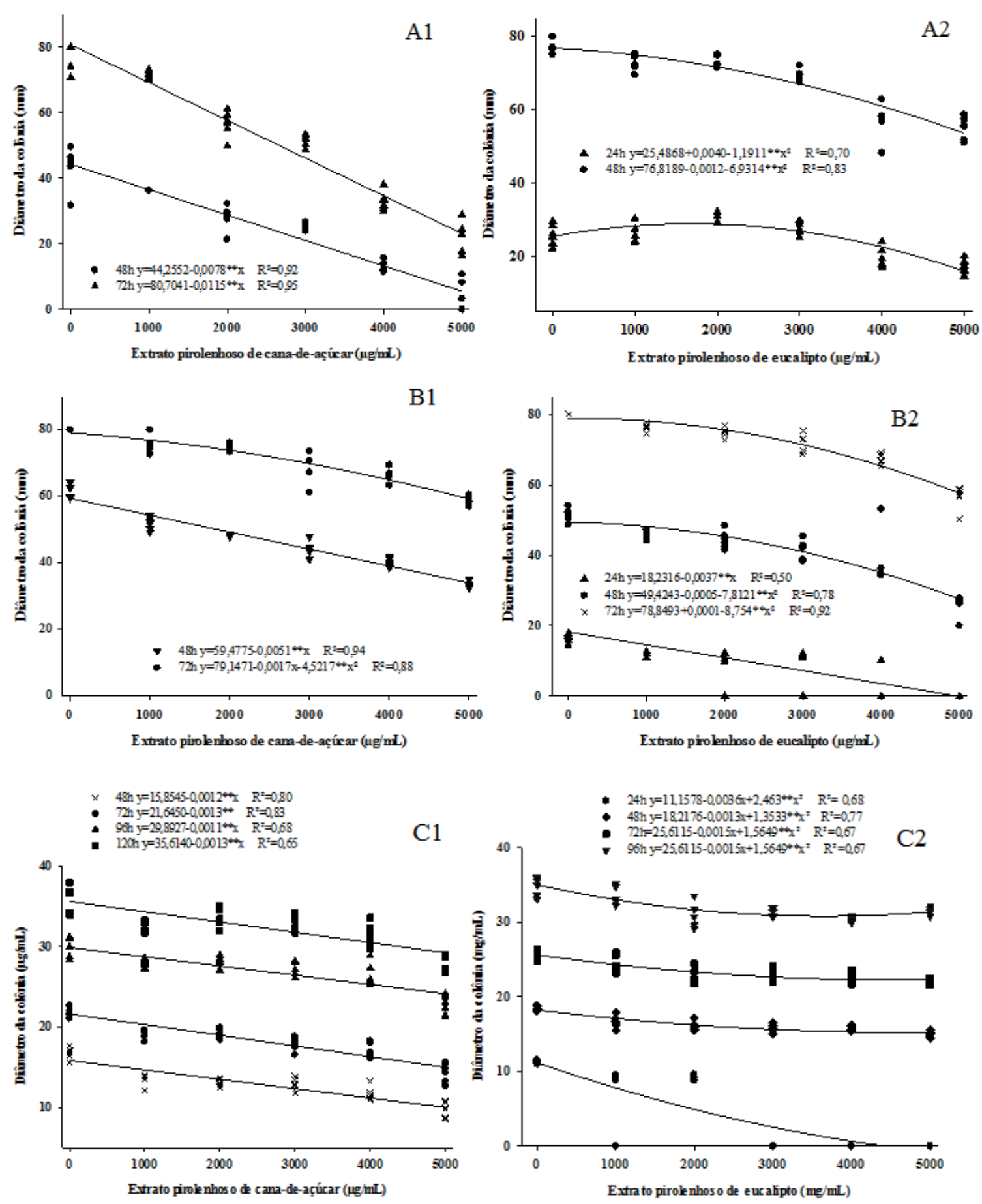

Figura 1. Crescimento micelial (mm) do fungo Sclerotinia sclerotiorum (A), Macrophomina phaseolina (B) e Colletotrichum truncatum (C) sob influência de diferentes concentrações de extrato pirolenhoso de cana-de-açúcar (1) e eucalipto (2).

que cada espécie fúngica possui sensibilidade diferenciada aos componentes químicos do extrato e entre seus componentes, alguns podem inibir ou favorecer o desenvolvimento fúngico. De acordo com Kartal et al. (5), a composição do EP depende das condições do processo como a temperatura, o processo de fabricação e a composição do material utilizado. Segundo Saigusa (8), o efeito ativador ou inibidor do EP sobre os organismos vivos depende de sua concentração. Baimark et al. (1) relatam que o ácido acético e os compostos fenólicos presentes no extrato de Eucalyptus globulus, promovem a inibição do crescimento fúngico. Os resultados encontrados pelos autores citados podem explicar a diferente ação dos EP de cana-de-açúcar e eucalipto nos fungos analisados neste estudo. Apesar das diferentes respostas, ambos os extratos exerceram ação fungitóxica direta sobre o crescimento in vitro dos fungos, sendo o primeiro passo para identificar o potencial desse produto no controle de fitopatógenos. Desta forma, conclui-se que a concentração de $5000 \mu \mathrm{g} / \mathrm{mL}$ dos EP de cana-de-açúcar e eucalipto apresentaram atividade antifúngica sobre $S$. sclerotiorum, $M$. phaseolina, C. truncatum. Os extratos em geral apresentaram 
fungitoxicidade nas diferentes concentrações. Pesquisas in vivo devem ser realizadas para a comprovação de sua eficiência, avaliando a resposta dos mesmos quando em interação com fatores ambientais em situações de cultivo a campo.

\section{AGRADECIMENTOS}

À CAPES pelo apoio financeiro e científico. À empresa Bioware Tecnologia, pelo fornecimento dos extratos.

\section{REFERÊNCIAS}

1. BAIMARK, Y.; THREEPROM, J.; DUMRONGCHAI, N.; SRISUWAN, Y.; KOTSAENG, N. Utilization of wood vinegars as sustainable coagulation and antifungal agents in the production of natural rubber sheets. Journal of Environmental Science and Technology, Deira, Dubai, Emirados Árabes Unidos, v.1, n.4, p.157-163, 2008.

2. CAMPOS, A.D. Técnicas para produção de extrato pirolenhoso para uso agrícola. Pelotas: Embrapa Clima Temperado, 2007. 8p. (Circular Técnica, 65).

3. ENGASP. Estudo para o aproveitamento dos extratos pirolenhosos e as suas aplicações agrícolas: projeto n. 34001. [S. l.]: Ibero Massa Florestal, 2014.

4. FERREIRA, D.F. SISVAR: Sistema de Análise de Variância. Versão 5.6. Lavras: DEX/UFLA, 2003.
5. KARTAL, S.N.; IMAMURA, Y.; TSUCHIYA, F.; OHSATO, K. Preliminary evaluation of fungicidal and termiticidal activities of filtrates from biomass slurry fuel production. Bioresource Technology, Amsterdã, Holanda, v.95, n.1, p.41-47, 2004

6. MUELLER, D.; WISE, K.; SISSON, A.; SMITH, D.; SIKORA, E.; BRADLEY, C.; ROBERTSON, A. Understanding Soybean Diseases and Disorders. In: Mueller, D.; Wise, K.; Sisson, A.; Smith, D.; Sikora, E.; Bradley, C.; Robertson, A. (ed.). A farmer's guide to soybean diseases. St. Paul: APS Press, 2016. p.5-21.

7. RODRIGUES, C. Uso de extrato pirolenhoso de teca (Tectona grandis) no controle alternativo in vitro de Colletotrichum gloeosporioides. 2014. 74f. Dissertação (Mestrado em Biodiversidade e Agroecossistemas Amazônicos) - Universidade do Estado de Mato Grosso, Alta Floresta.

8. SAIGUSA, T. Aplicação de extrato pirolenhoso na agricultura. São Paulo: Associação dos Produtores de Agricultura Natural, 2002.

9. SANTOS JUNIOR, A.C.; RODRIGUES, J.M.A.; OLIVEIRA, R.; RODRIGUES, C.; DAVID, G.Q.; PERES, W.M. Fungitoxidade do extrato pirolenhoso ao fungo Rhizoctonia solani. In: Seminário de Biodiversidade e Agroecossistemas Amazônicos, 1., 2013, Alta Floresta. Anais. Alta Floresta, MT: PPGBioAgro, 2013. Disponível em: $<$ http://portal.unemat.br/media/files/FUNGITOXIDADE\%20DO\%20EXTRATO\%20PIROLENHOSO $\% 20$ AO\%20FUNGO\%20Rhizoctonia\%20solani.pdf $>$. Acesso em: 04 dez. 2016.

10. SILVEIRA, C.M.S. Influência do extrato pirolenhoso no desenvolvimento e crescimento de plantas de milho. 2010. 93f. Tese (Doutorado em Agronomia) - Universidade Estadual Paulista, Jaboticabal.

11. THEISEN, G.; CAMPOS, A.D.; NUNES, C.D.; LUCAS, M.K. Efeitos de extratos pirolenhosos utilizados como tratamento de sementes sobre doenças da fase inicial e crescimento de plântulas de soja. Pelotas: Embrapa Clima Temperado, 2010. (Comunicado Técnico, 241). 